\title{
Multiscale Design Strategies in a Landscape Architecture Classroom
}

Nic Lupfer

Hannah Fowler

Alyssa Valdez

Interface Ecology Lab

Texas A\&M University

College Station, TX 77843 USA

nic@ecologylab.net

hannah.fowler1217@tamu.edu

alyssavaldez@tamu.edu

\section{Andrew M. Webb}

LRI, Univ. Paris-Sud, CNRS

Inria, Université Paris-Saclay

Orsay, France

andrew.webb@Iri.fr

Permission to make digital or hard copies of all or part of this work for personal or classroom use is granted without fee provided that copies are not made or distributed for profit or commercial advantage and that copies bear this notice and the full citation on the first page. Copyrights for components of this work owned by others than the author(s) must be honored. Abstracting with credit is permitted. To copy otherwise, or republish, to post on servers or to redistribute to lists, requires prior specific permission and/or a fee. Request permissions from Permissions@acm.org.

DIS '18, June 9-13, 2018, , Hong Kong

(c) 2018 Copyright is held by the owner/author(s). Publication rights licensed to ACM.

ACM ISBN 978-1-4503-5198-0/18/06 \$15.00

https://doi.org/10.1145/3196709.3196812

\author{
Jeremy Merrill \\ Galen Newman \\ Department of Landscape Archi- \\ tecture Urban Planning \\ Texas A\&M University \\ College Station, TX 77843 USA \\ jmerrill42@tamu.edu \\ gnewman@arch.tamu.edu

\section{Andruid Kerne} \\ Interface Ecology Lab \\ Texas A\&M University \\ College Station, TX 77843 USA \\ andruid@ecologylab.net \\ Archi-
}

Abstract

We derive a theory of multiscale design through a study of a landscape architecture studio classroom. We find that processes of designing, to meet a site's situated needs, involve creating and connecting representations across levels, such as overview and detail. We introduce multiscale design theory, which works to understand how designers explore, juxtapose, and synthesize relationships across levels of scale. We identify three design strategies landscape architecture students use to work with scale: multiply, map, and shift perspective. We combine these strategies with prior literature, across fields, to initiate a theory of multiscale design.

\section{Authors Keywords}

Design, scale, visual representation, visual design, multiscale, visual grounded theory

\section{ACM Classification Keywords}

H.5.m [Information interfaces and presentation]

\section{Introduction}

We study design practices in a landscape architecture studio classroom. Like others [19], we find that architecture studio contexts provide unique opportunities for people to engage in collaborative practices, which are social, embodied, and experiential in nature. In performing studio projects, students define multiple problems facing a site, in conjunction with analyzing information scales spanning site, local, regional, national, and global [5]. 
Student designers synthesize analysis components, crossing a variety of contexts and scales, to develop sets of design proposals, both conceptual and schematic, which address encountered problems. They engage in a process intended to encourage them to enter into a dialectic relationship with the site and design dilemma. They must propose ultimate particular [15] solutions, which map directly on to the site, while at the same time analyzing these solutions in terms of larger contexts [14]

As their design evolves, students must shift their thinking across scales, to connect and relate their design to personal, civil, social, and environmental processes.

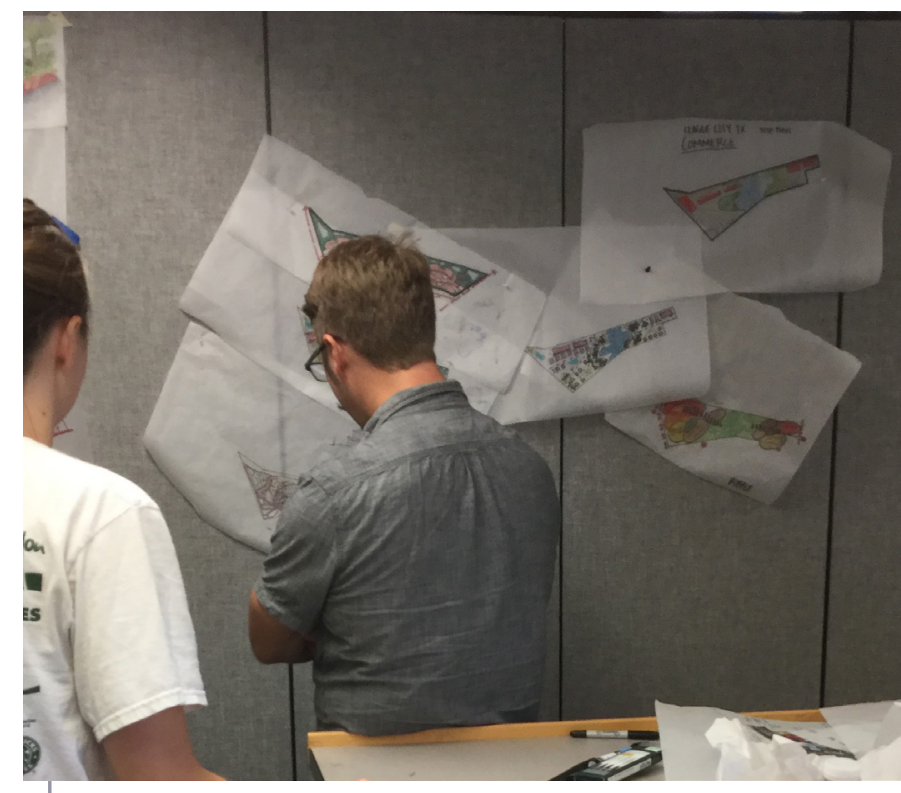

Students pin their sketches and drawings to walls to spatially organize them. In this picture, an instructor is talking with students about their sketches.

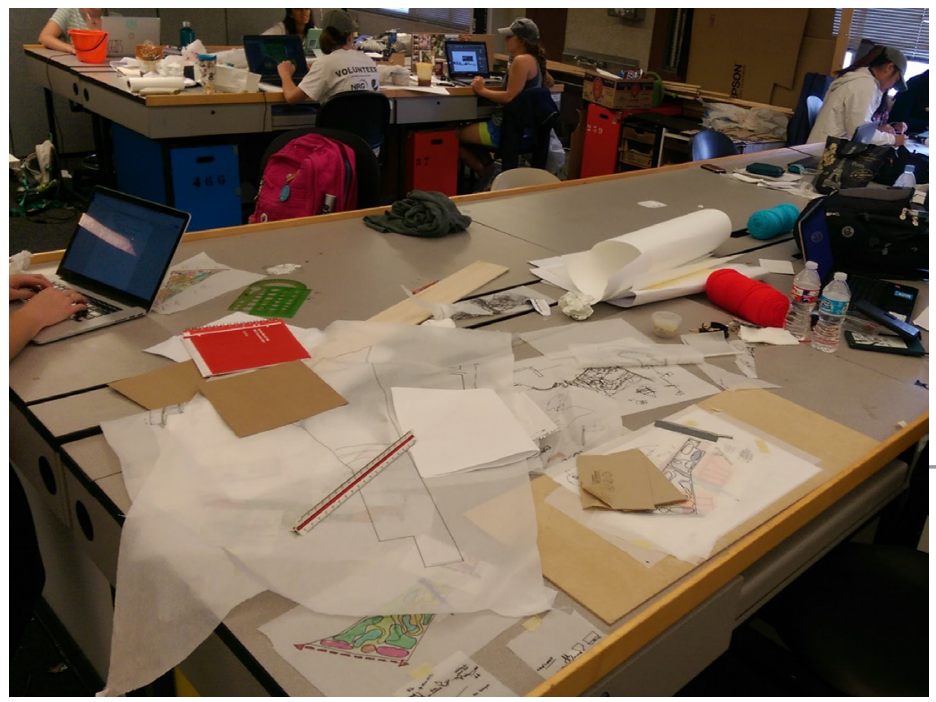

In the studio space, students are assigned desks in clusters with their other team members. The desks were often covered with sketches and tracing

paper.

\section{Methodology}

Our understanding of multiscale design comes from sustained study of an undergraduate level landscape architecture design studio course, Landscape Design III. The course had 3 instructors and 20 students. The students were divided into 6 teams, each with between 3 and 5 members. The course included some traditional lectures, but primarily focused on studio sessions, in which student teams worked on their projects alongside instructors.

The course is structured around a semester-long project, in which all teams are given the same landscape site and design problem to solve. During the semester of our investigation, the specific problem involved a 97-acre region in League City, Texas, USA. The task was to design a development plan for the site, involving both residential and commercial properties, which addressed projected sea-level rise and increasing housing needs. 


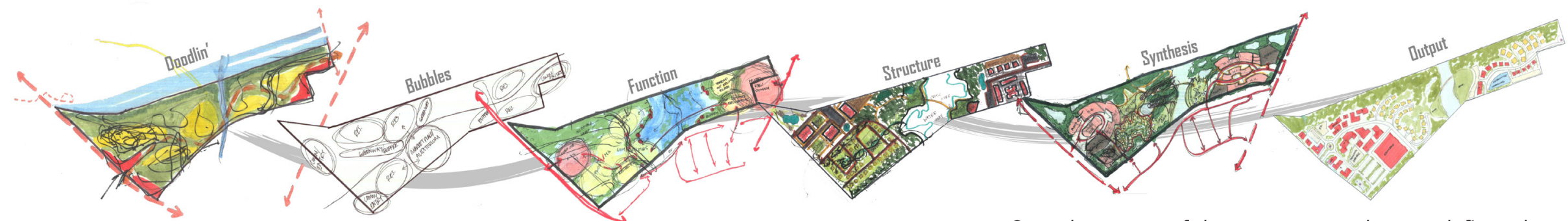

The above graphic, taken from Team ReSTORE's final poster, shows the stages of their design process. They included this graphic in their final poster to show, as P4 states, "So you're starting at the beginning and go through what we went through."

From left to right, the labels read: Doodlin', Bubbles, Function, Structure, Synthesis, Output.

This collection of images manifests the multiply strategy, using the repeated shape of the problem site to convey change.

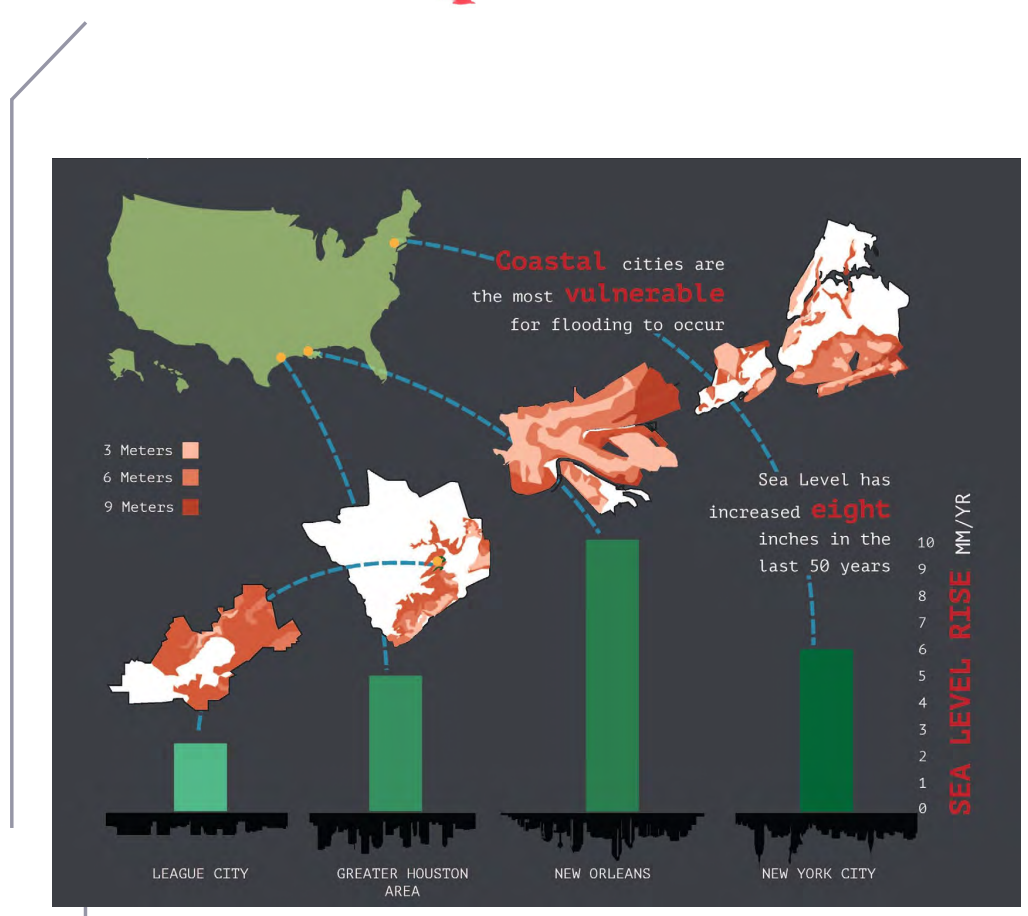

The above infographic, created by Team FAD Visions, contextualizes the design task. The image introduces the problem of sea level rise, comparing projected effects among different United States coastal metropolitan areas: League City, TX, New Orleans, LA, and New York, NY.
Over the course of the semester, each team defines the problems facing the site, analyzing information at the regional, city, and site levels. Next, they must conceptually and schematically develop a set of design proposals addressing these problems.

Like prior ethnographic studies of design studios [19], our methodology is focused on the design artifacts and the associated practices. Our collected data includes observations of the course, interviews with students, and the students' design artifacts. We observed 13 classroom / studio sessions, making notes and taking pictures of students working and interacting with instructors. Observation sessions were mostly studio work periods; others were lectures or student presentations.

At the end of the semester, we performed one-on-one, semi-structured interviews with 5 students from two of the teams: 3 from Team FAD Visions (P2, P3, P5), and 2 from Team ReSTORE (P1, P4). Interviews were analyzed using the grounded theory method of open coding [4] Additionally, we collected design artifacts from these two teams. These artifacts were taken from different stages of their design processes. Using a visual grounded theory approach $[9,11]$, we categorized the artifacts based on their visual features. From this, we derived strategies, i.e., discursive, open-ended descriptors for how people approach and engage in creative processes [8]. We identified three main strategies: multiply, map, and shift perspective. 


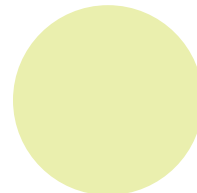

\section{Strategy: Multiply}

The multiply strategy involves using repeated forms to connect information from different scales into a single, fixed contextual area and scale. These artifacts constitute small multiples. Small multiples support connecting information across scales by "visually enforcing comparisons of changes" [17].

The information presented in each multiple may be cropped to fit a target extent. The fixed scale of the repeated extent supports thinking about and comparing the different aspects of a design, without having to make mental scale conversions.

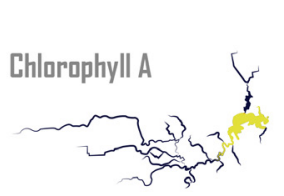

Land cover impairments from land use are found in food, water, and the environment.

They are hazardous to human health and decrease the quality of life.
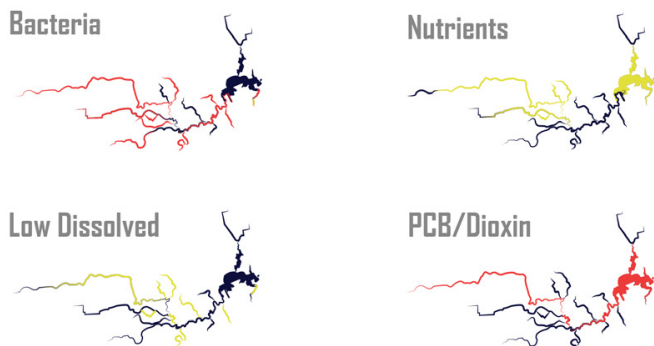
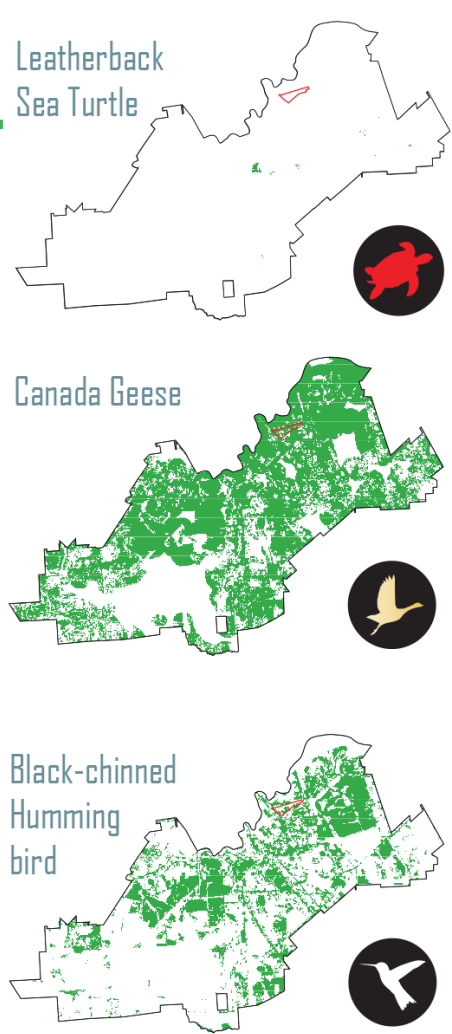

In this example, the repeated shape is that of the waterways in League City. These water ways include the Gulf of Mexico, Texas rivers, and many smaller canals and regions.
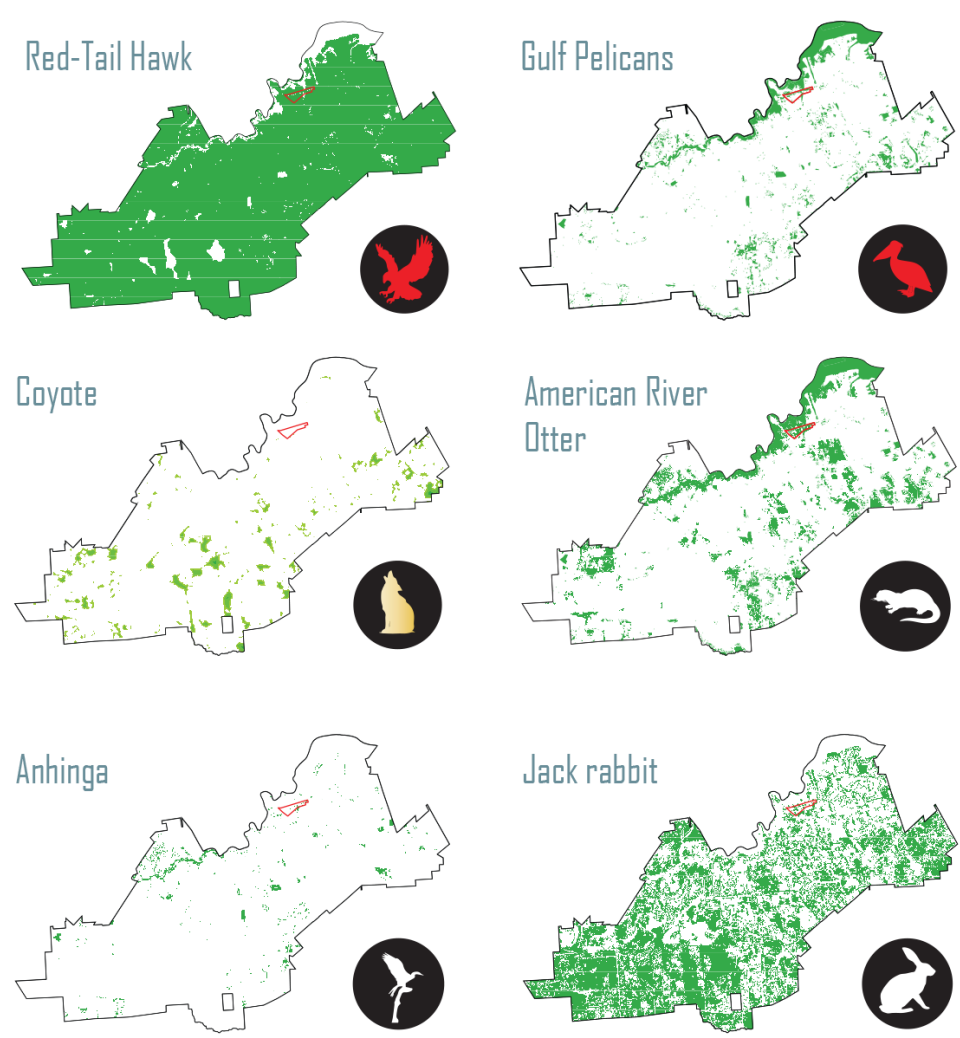

These multiples of League City, arranged in a $3 \times 3$ grid, show some of the different animal populations in the area. The red animal icons indicate endangered species and the yellow indicate migratory species. Each of the species shown has different scales of habitats, especially the migratory species. Using multiples, the students were able to relate the different habitat scales to a single scale, that of League City. Additionally, they have placed a small red outline which highlights the specific 97 acre project site. 


\section{Strategy: Multiply}

Through this strategy, the repeated shape or silhouette encapsulates layers of information. Multiply thus draws on the stratification principle: "The city consists of a stratification of layers forming a consolidated entity" [2]. While presented information may address larger scale phenomena, such as animal migration or flood plains, repeated shape and scale ground and contextualize understanding.

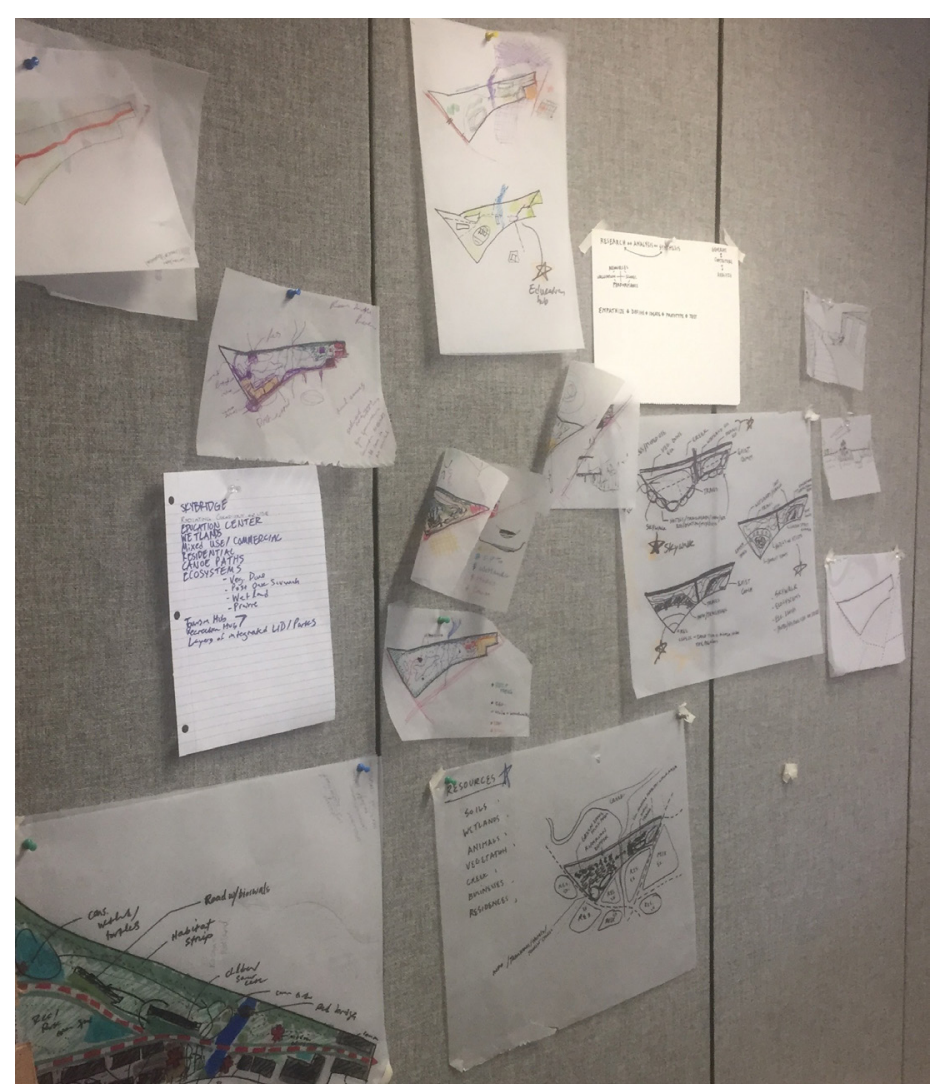

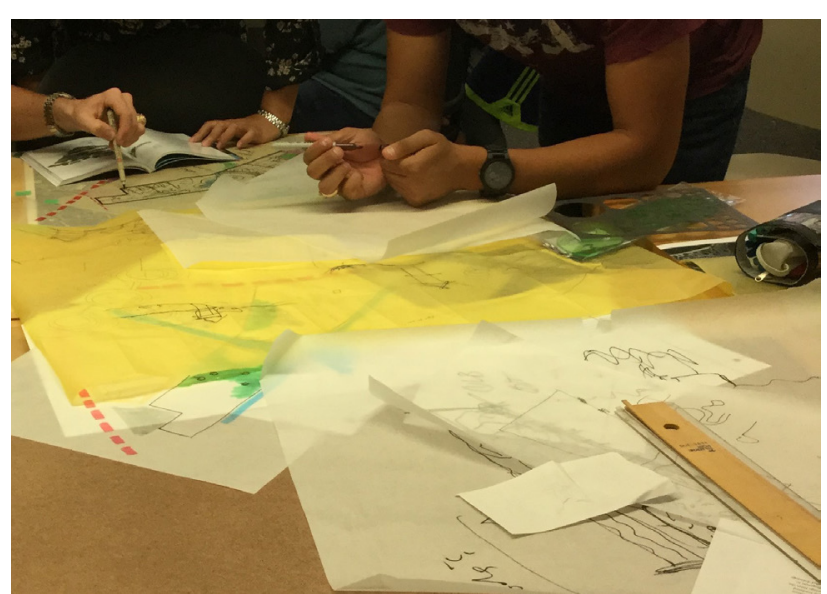

Tracing paper is very common in the landscape architecture studio. Through tracing, students are able to quickly and easily duplicate shapes and diagrams. As P4 explains, "[Paper] more freeform and you're allow to explore different forms".

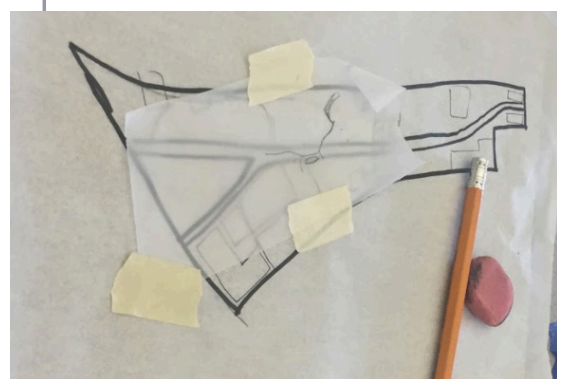

We also observed students printing multiple copies of an artifact and then sketching over and annotating each with different types or scopes of information. The printouts on the right are labelled, from top to bottom, Design Problem, LID (low impact development), Sections, Transportation, and Original.

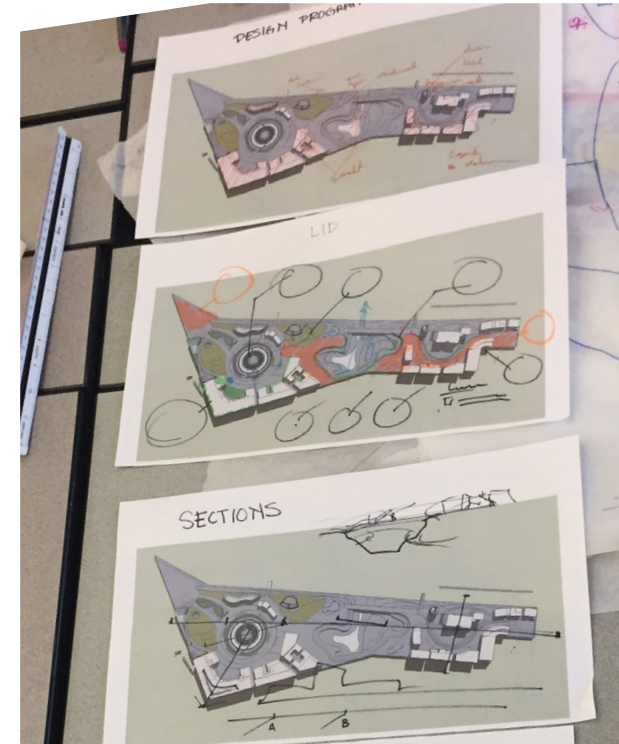

TRANSFORTA HONS

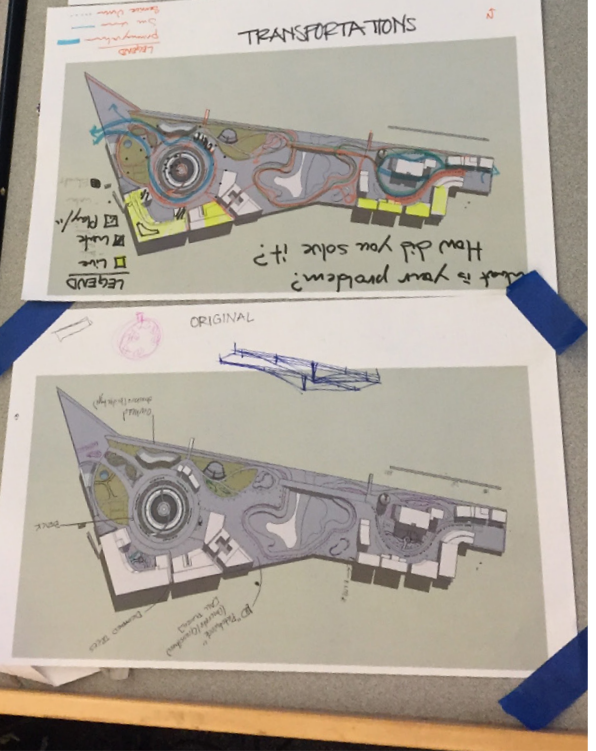




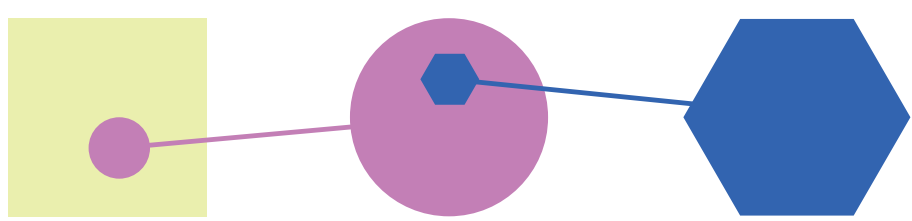

\section{Strategy: Map}

The map strategy involves defining spatial relationships between representational elements. The artifacts created with this strategy are similar to traditional maps in their indexical nature, in which the meaning of elements is derived from their context [18]. Mapping involves using visual techniques, such as layering or callouts, to connect the elements. Callouts are often lines or shapes, which relate one artifact into the space and scale of another artifact. Mapping facilitates connecting contexts of different scales through abstract visual scale transitions. Scale transitions can be in either direction, zooming out to show encompassing contexts or zooming in to show nested details. These transitions of scale are similar to the embodied experience of the city today, which Allen describes as, "Not so much the orderly progression of scales, as an experience of rapid shifts in scale and speed" [1].

A map of the elevation is placed above an aerial view rendering of the site and the existing surrounding development. The dashed gray lines are used as callouts, to show how the Elevation Relief map fits into Surrounding Context of the problem site. The Elevation Relief map is used to help them easily understand how to prevent sealevel rise and flooding from nearby development.

This is a good example of how strategies work together. In this artifact, the shape of the specific site is multiplied but each is shown from a different scale and perspective.

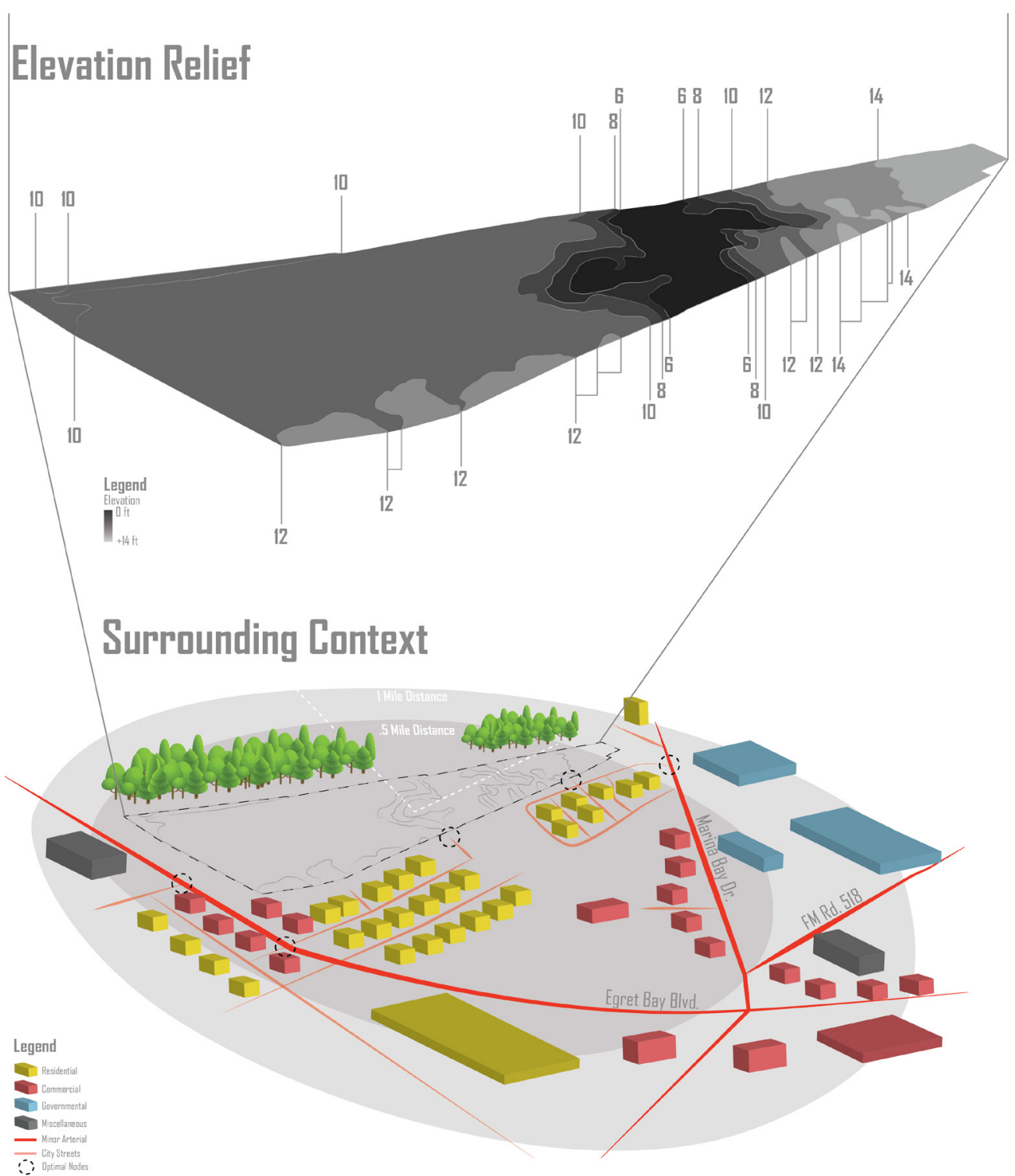




\section{Strategy: Map}

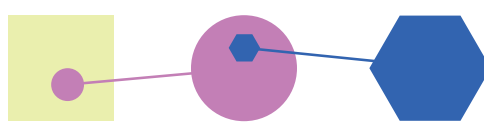

Overlaid on top of a global map, Team FAD Visions has placed images of the state of Texas, League City, and the specific design site. They use callouts

to place Texas within the world map, League City within Texas, and the design site within League City.
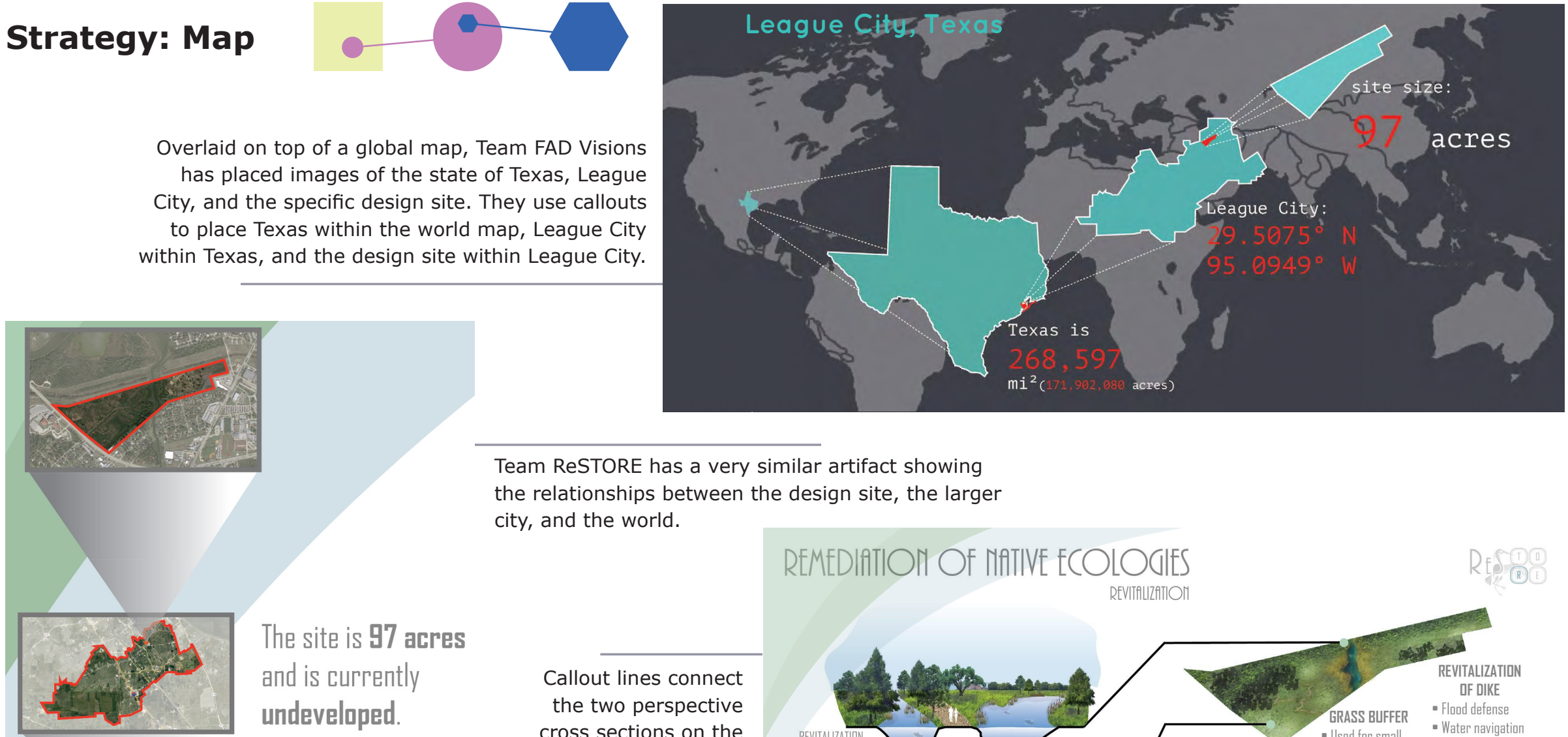

Team ReSTORE has a very similar artifact showing

the relationships between the design site, the larger

city, and the world.

The site is $\mathbf{9 7}$ acres and is currently undevelaped.

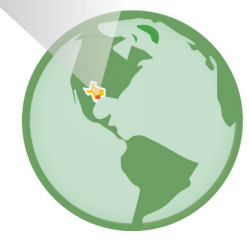

Callout lines connect the two perspective cross sections on the left with their respective locations within the site map on the top right.

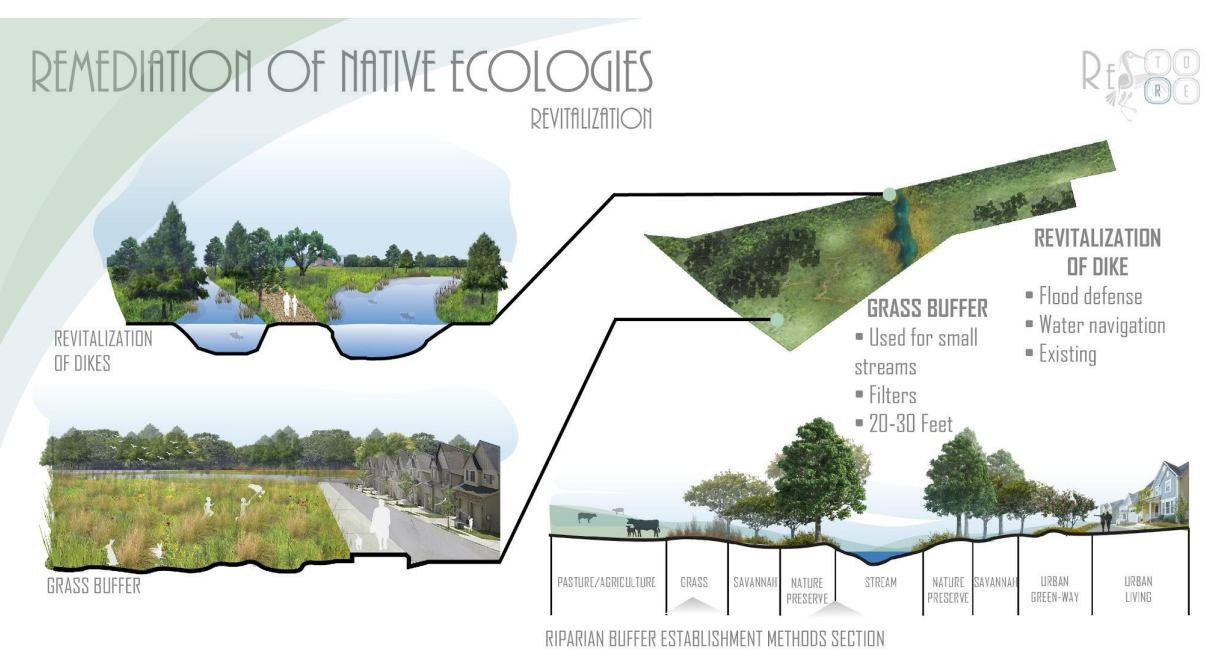




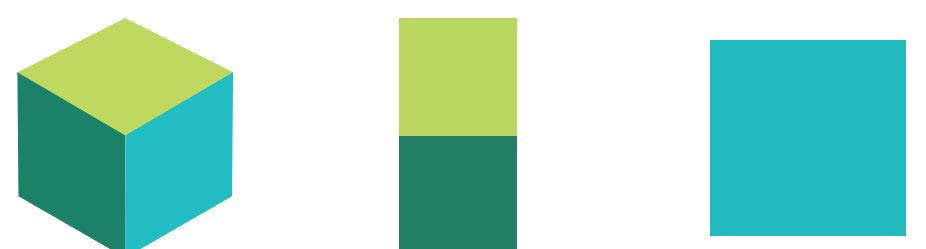

\section{Strategy: Shift Perspective}

The shift perspective strategy involves using views from different zoom levels and angles to gain a wider understanding of a context. We observed this strategy manifesting through models, either digital or physical, and through perspective renderings, such as bird's eye, cross section, and ground level views. Shift perspective is sometimes invoked in conjunction with the map strategy to situate perspective views among other representations.

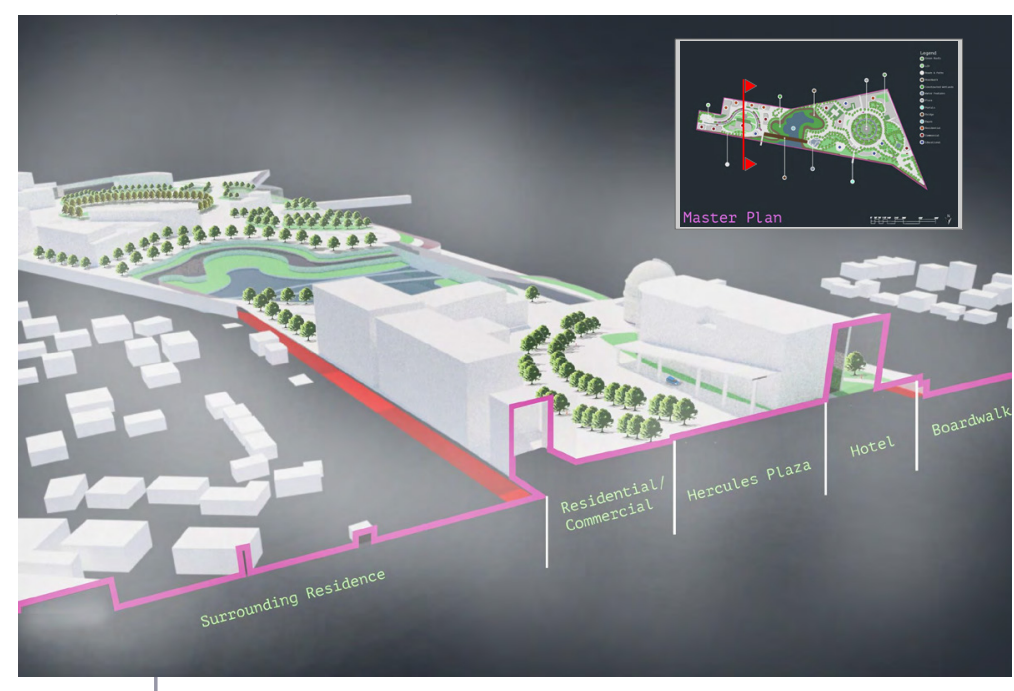

Students created 3D models of the site using SketchUp and AutoCAD to easily see how their designs fit together within different contexts. The models helped them see issues and other aspects that needed to be addressed that may have been overlooked before the model. In P2's words, "The [3D] model made us realize how big things were, [we needed to] scale things differently... Because we realized 'that's too big' or 'we need to make that smaller"'. P4 echoes this sentiment, saying "We put it to scale so that it wasn't just random anymore and that way we actually knew where stuff could go".

In the above design artifact, Team FAD Visions is showing a cross section view of their 3D model of their proposal for the site. They also included an overview image of the their "Master Plan" in the top right. The red line in the overview is a form of the map strategy, connecting the cross section to its location within the "Master Plan". 


\section{Strategy: Shift Perspective}

Physical models manifest a form of the shift perspective strategy. They stimulate embodied cognition by situating the viewer relative to their 3D spatial forms $[10,7]$. The way in which one transitions between perspectives when viewing a physical model is similar to the continuous transitions of scale within zoomable free-form spaces [8]. Experiencing the variability of relationships between designer and problem contexts has the potential to function as provocative stimuli [13], which can help overcome fixation. We also see students manifest other multiscale strategies within their physical models, further extending a model's use as embodied, spatial metaphor [10].

Students created physical models of the design site and surrounding areas to help them visualize and understand the context.

In their physical model, Team FAD Visions placed their design proposal as a removable section which stood on stilts above the model of the original version of the site. P2 explains, "We wanted it to show how the site changes".
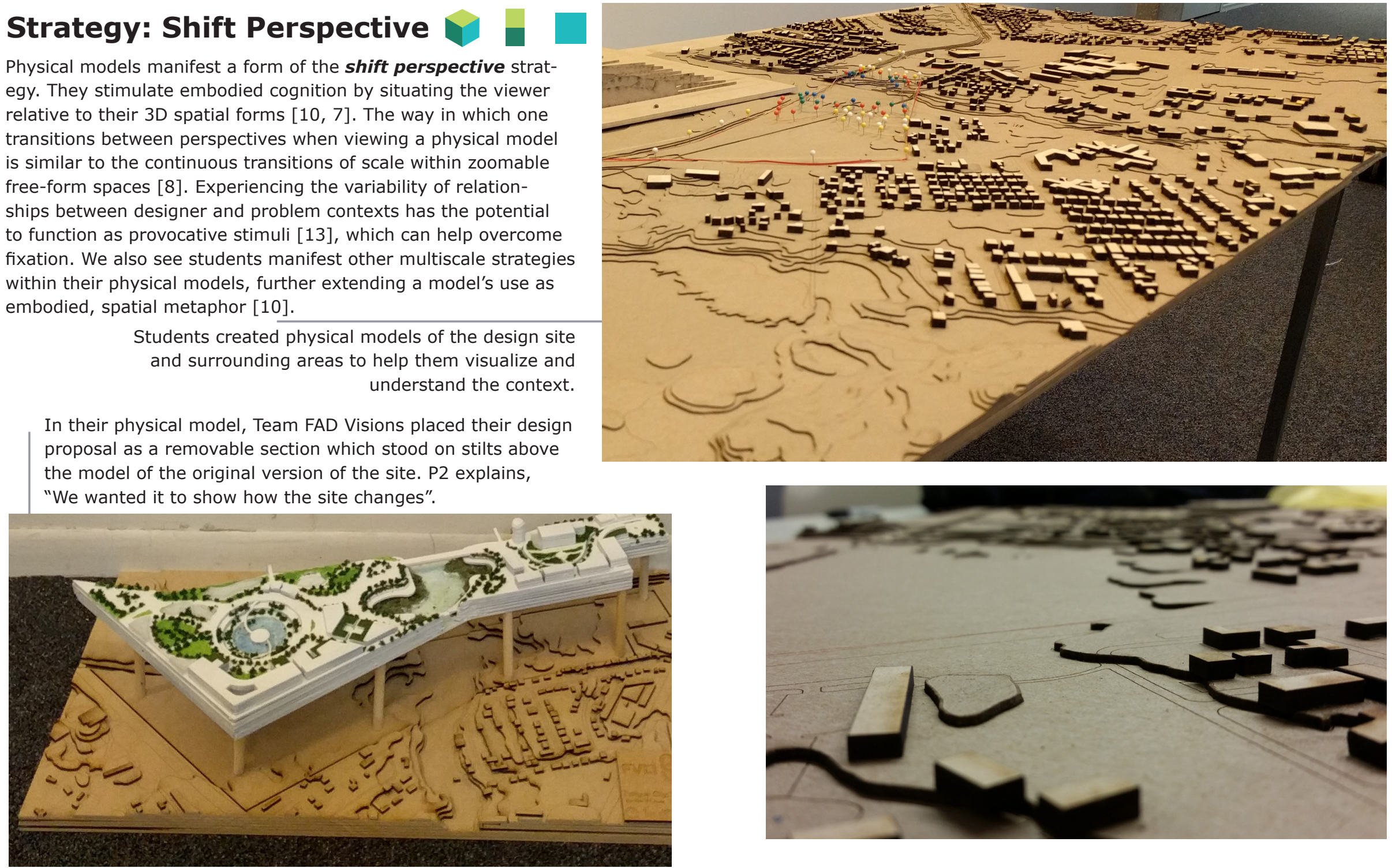


\section{Strategy: Shift Perspective}

Other types of artifacts that students used to invoke the shift perspective strategy include cross sections and human level, detailed, renderings. Students used these artifacts to, "Give you what the topography looks like [and] show you scale-wise what a human would relate to" [P2].

These ground level renderings of residential and business development demonstrate proposed solutions for dealing with excess water and flooding. When questioned about her process creating these perspective renderings, P4 says, "It depends on how much detail you want to put into it...I will zoom in, like micro, to try to fix stuff because I'm kind of a perfectionist."

\section{Pecking Grounds Paving}

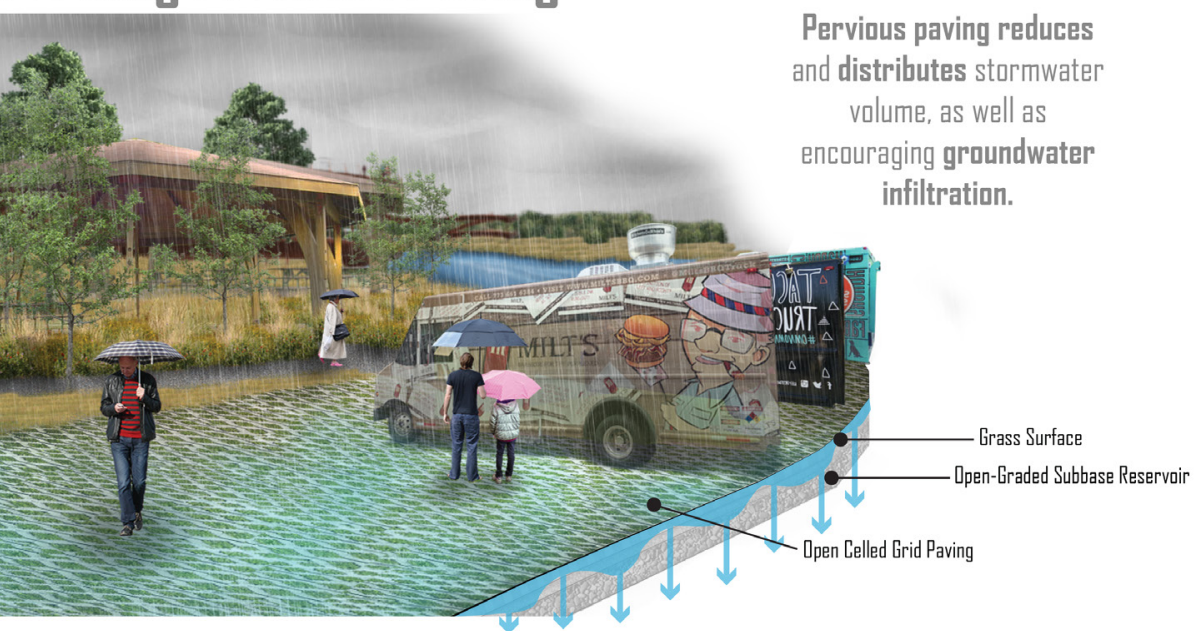

Commercial District

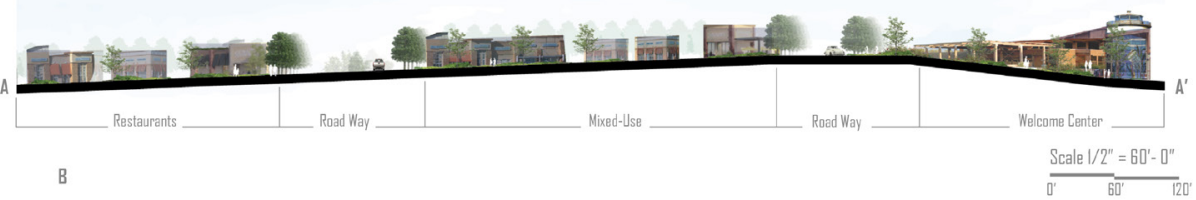

The Wedge Community

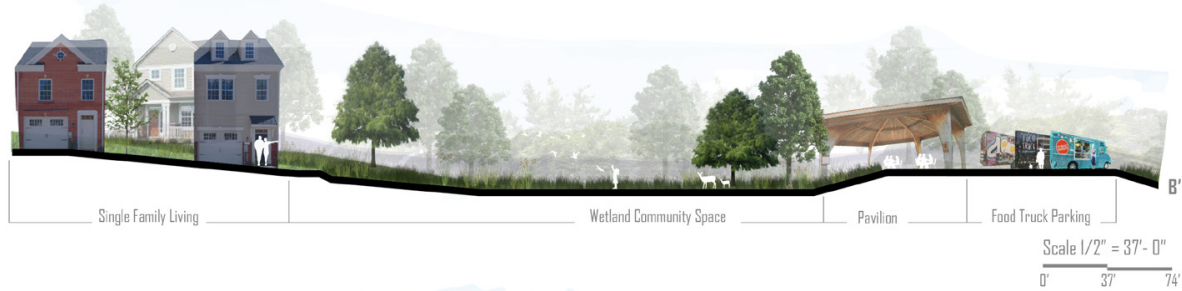

These two cross section perspectives, while set to different scales, compare and contrast the topology of these two districts of Team ReSTORE's design proposal.

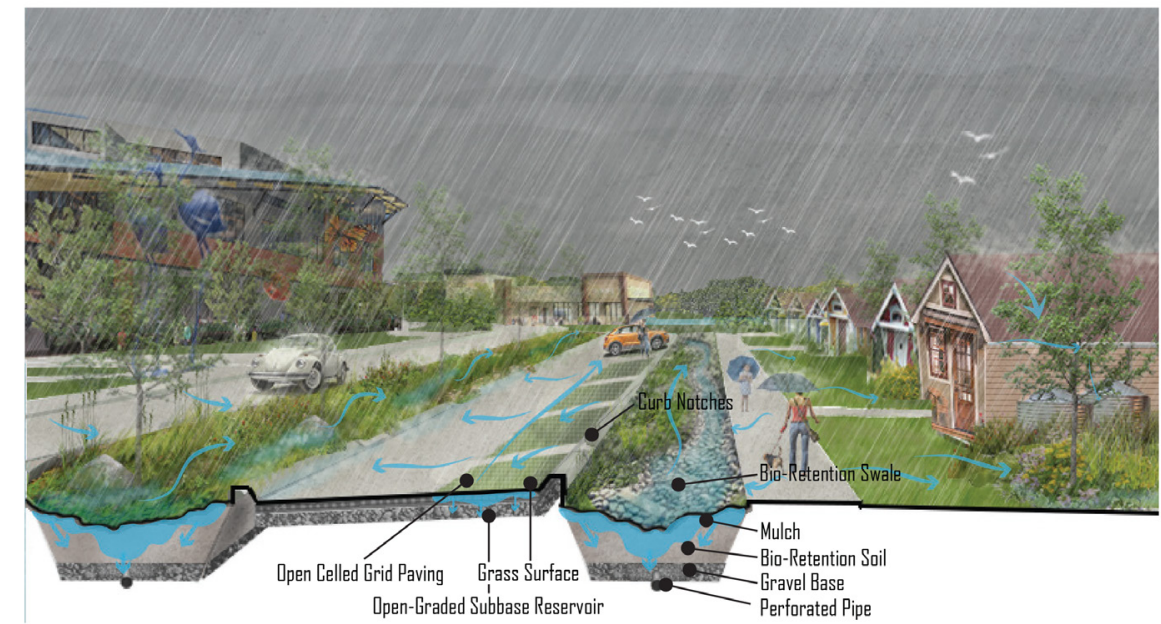



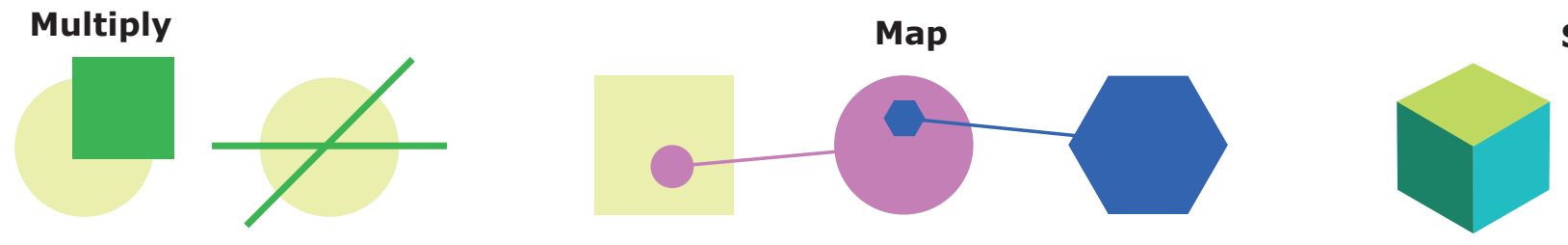

Shift Perspective

\section{Multiscale Design Theory}

Our work to formulate theory begins with understanding how student designers think about and deal with scale during design processes. We made observations, performed interviews, and collected and analyzed their design artifacts. From this data, we identified three visual design strategies that they used to deal with scale: multiply, map, and shift perspective.

The strategies are interconnected. They often appear in conjunction with one another. Students multiply to explore and create different representations of a design context. They map these, and other, representations together to connect and relate them. And through these mappings, they are assisted in shifting perspectives, to see the context through multiple vantage points. These strategies work together, helping the students understand the design context as a whole. Multiply and map, in combination, represent particular ways of performing free-form curation's assemble strategy [8], that is, structured ways of putting content elements together. The assemble strategy was found to be significant in processes of design ideation involving invention and prior work.

We synthesize the strategies to initiate a theory of multiscale design. We define multiscale design as the use of space and scale to explore and articulate relationships. Multiscale design involves the juxtaposition and synthesis of diverse design elements--including physical, geographic, and abstract representations-- and through these elements, the contexts in which they are situated.
Next, to abstract from our findings, we mesh this new theory of multiscale design with prevailing theory. As mathematical biologist, D'Arcy Wentworth Thompson states, "The effect of scale depends not on a thing itself, but in relation to its whole environment or milieu" [16]. Architecture theorist Stan Allen claims, "Form matters, but not so much the forms of things, as the form between things"[1]. Another theorist, Corajoud, explains, "Crossing through scales is about controlling simultaneously and in the same way, the general and the specific, the close and the far" [3]. Multiscale design theory addresses ways in which design representations facilitate "crossing scales".

Architecture students work with and think about representations in a nonlinear manner across scales [12]. They need to present large amounts of information that often possess multiple relationships to other parts of their design. Prior theory contributes to our understanding. Ellin's understanding of the role of scale contributes to multiscale design theory, by shifting focus to, "Process rather than the product, relationship (or context) rather than isolated objects, and complementary rather than opposition" [6].

The practice of multiscale design strategies, in landscape architecture studio classrooms, contributes a model for future research, to explore new methods and interaction techniques supporting multiscale design. We hypothesize that multiply, map, and shift perspective strategies represent an initial set of discursive creative methods for seeing and doing multiscale design. Future work can then investigate to what extent the present theory is generalizable or context specific and how multiscale design is alternatively performed. These studies need to address various educational and professional design studio contexts. 


\section{Acknowledgements}

This material is based upon work supported by the $\mathrm{Na}$ tional Science Foundation under grant IIS-1247126. Any opinions, findings, and conclusions, or recommendations expressed in this material are those of the authors and do not necessarily reflect the views of the NSF.

\section{References}

1. Stan Allen. 1997. From object to field+ Architecture and urbanism. Architectural design 127 (1997), 24-31.2.

2. Marc Angélil and Anna Klingmann. 1999. Hybrid Morphologies - Infrastructure, Architecture, Landscape. Daidalos 73 (1999), 16-25.

3. Jean-Luc Brisson, Emmanuelle Passerieux, and Delphine Gorges. 2000. Le jardinier, l'artiste et I'ingénieur. Les Ed. de I'Imprimeur.

4. Kathy Charmaz and Linda Liska Belgrave. 2007. Grounded theory. Wiley Online Library.

5. Siqing Chen and Virginia Lee. 2015. From metropolis to allotment: Scaled system thinking in advancing landscape studio knowledge. Buhmann $\mathrm{E}$ et al. (eds,2015) Systems Thinking in Landscape Planning and Design: Landscape Architecture 3 (2015), 344353.

6. Nan Ellin. 2006. Integral urbanism. Taylor \& Francis.

7. Arthur M Glenberg and William E Langston. 1992.
Comprehension of illustrated text: Pictures help to build mental models. Journal of Memory and Language 31, 2(1992), 129-151.

8. Andruid Kerne, Nic Lupfer, Rhema Linder, Yin Qu, Alyssa Valdez, Ajit Jain, Kade Keith, Matthew Carrasco, Jorge Vanegas, and Andrew Billingsley. 2017. Strategies of Free-Form Web Curation: Processes of Creative Engagement with Prior Work. In Proceedings of the 2017 ACM SIGCHI Conference on Creativity and Cognition (C\&C '17). 380-392.

9. Krzysztof Tomasz Konecki. 2011. Visual grounded theory: A methodological outline and examples from empirical work. Revija za sociologiju 41, 2 (2011), $131-160$

10. George Lakoff and Mark Johnson. 1980. Conceptual metaphor in everyday language. The journal of Philosophy 77, 8 (1980), 453-486.

11. Nic Lupfer, Andruid Kerne, Andrew M Webb, and Rhema Linder. 2016. Patterns of free-form curation Visual thinking with web content. In Proceedings of the ACM Conference on Multimedia. 12-21.

12. Steffen Nijhuis, Egbert Stolk, and Maarten Jan Hoekstra. 2016. Teaching urbanism: the Delft approach. Proceedings of the Institution of Civil Engineers-Urban Design and Planning 170, 3 (2016),96-106. 


\section{References}

13. Steven M Smith, Nicholas W Kohn, and Jami Shah 2008. What you see is what you get: Effects of provocative stimuli in creative invention. In Proceedings of the NSF International Workshop on Studying Design Creativity.

14. Robert Smithson. 1973. Frederick Law Olmsted and the dialectical landscape. Robert Smithson 164 (1973).

15. Erik Stolterman. 2008. The nature of design practice and implications for interaction design research. International Journal of Design 2, 1 (2008).
16. Darcy Wentworth Thompson and others. 1942. On growth and form. On growth and form. (1942).

17. Edward R. Tufte. 1990. Envisioning Information Graphics Press, Cheshire, CT.

18. David Turnbull and Helen Watson. 1993. Maps Are Territories Science is an Atlas: A Portfolio of Exhibits. (1993).

19. Dhaval Vyas, Gerrit van der Veer, and Anton Nijholt. 2013. Creative practices in the design studio culture: collaboration and communication. Cognition, Technology \& Work 15, 4 (2013), 415-443. 